\title{
Prognostic factors for return to work after depression-related work disability : A systematic review and meta-analysis
}

\section{Ervasti, Jenni}

\author{
2017-12
}

Ervasti , J , Joensuu , M , Pentti , J , Oksanen , T, Ahola , K, Vahtera , J , Kivimaki , M \& Virtanen, M 2017 , ' Prognostic factors for return to work after depression-related work disability : A systematic review and meta-analysis ', Journal of Psychiatric Research, vol. 95 , pp. 28-36 . https://doi.org/10.1016/j.jpsychires.2017.07.024

http://hdl.handle.net/10138/298151

https://doi.org/10.1016/j.jpsychires.2017.07.024

publishedVersion

Downloaded from Helda, University of Helsinki institutional repository.

This is an electronic reprint of the original article.

This reprint may differ from the original in pagination and typographic detail.

Please cite the original version. 


\title{
Prognostic factors for return to work after depression-related work disability: A systematic review and meta-analysis
}

\author{
Jenni Ervasti a, *, Matti Joensuu a , Jaana Pentti a, Tuula Oksanen ${ }^{a}$, Kirsi Ahola ${ }^{\text {a }}$,

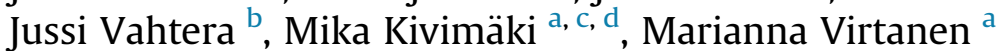 \\ ${ }^{a}$ Finnish Institute of Occupational Health, Helsinki, Finland \\ ${ }^{\mathrm{b}}$ Department of Public Health, University of Turku and Turku University Hospital, Turku, Finland \\ ${ }^{c}$ Clinicum, Faculty of Medicine, University of Helsinki, Finland \\ d Department of Epidemiology and Public Health, University College London, UK
}

\section{A R T I C L E I N F O}

\section{Article history:}

Received 29 December 2016

Received in revised form

10 July 2017

Accepted 24 July 2017

\section{Keywords:}

Clinical factors

Cohort studies

Sickness absence

Sociodemographic factors

Psychosocial work environment

\begin{abstract}
A B S T R A C T
Knowledge about factors influencing return to work (RTW) after depression-related absence is highly relevant, but the evidence is scattered. We performed a systematic search of PubMed and Embase databases up to February 1, 2016 to retrieve cohort studies on the association between various predictive factors and return to work among employees with depression for review and meta-analysis. We also analyzed unpublished data from the Finnish Public Sector study. Most-adjusted estimates were pooled using fixed effects meta-analysis. Eleven published studies fulfilled the eligibility criteria, representing 22358 person-observations from five different countries. With the additional unpublished data from the 14101 person-observations from the Finnish Public Sector study, the total number of personobservations was 36 459. The pooled estimates were derived from 2 to 5 studies, with the number of observations ranging from 260 to 26348 . Older age (pooled relative risk [RR] 0.95; 95\% confidence interval $[\mathrm{CI}] 0.84-0.87$ ), somatic comorbidity $(\mathrm{RR}=0.80,95 \% \mathrm{CI} 0.77-0.83)$, psychiatric comorbidity $(\mathrm{RR}=0.86,95 \% \mathrm{Cl} 0.83-0.88)$ and more severe depression $(\mathrm{RR}=0.96,95 \% \mathrm{CI} 0.94-0.98)$ were associated with a lower rate of return to work, and personality trait conscientiousness with higher $(R R=1.06,95 \%$ CI 1.02-1.10) return to work. While older age and clinical factors predicted slower return, significant heterogeneity was observed between the studies. There is a dearth of observational studies on the predictors of RTW after depression. Future research should pay attention to quality aspects and particularly focus on the role of workplace and labor market factors as well as individual and clinical characteristics on RTW.
\end{abstract}

๑) 2017 Elsevier Ltd. All rights reserved.

\section{Contents}

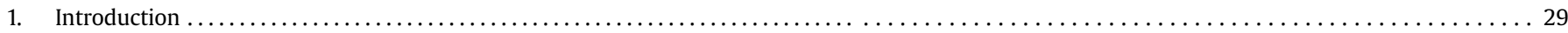

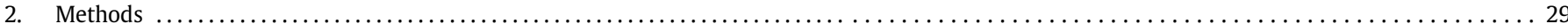

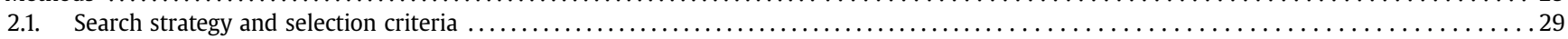

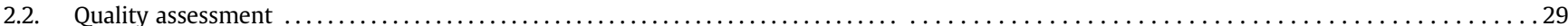

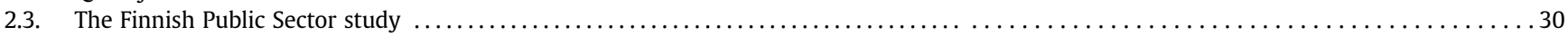

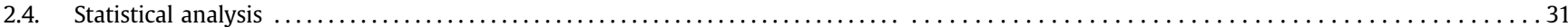

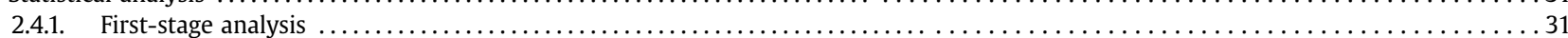

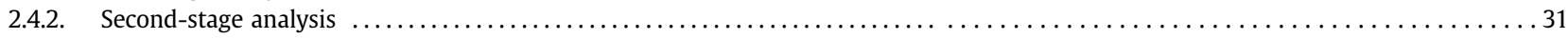

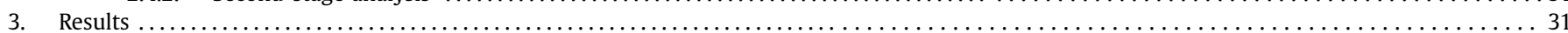

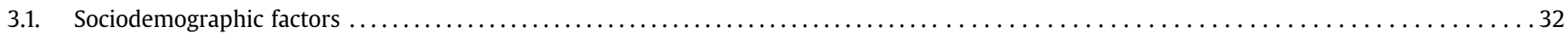

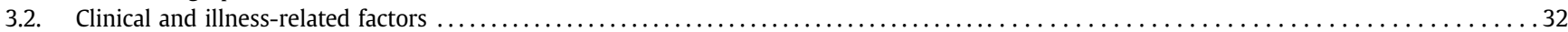

\footnotetext{
* Corresponding author. Finnish Institute of Occupational Health, PB 40, FI-00251 Helsinki, Finland.

E-mail address: jenni.ervasti@ttl.fi (J. Ervasti).
} 


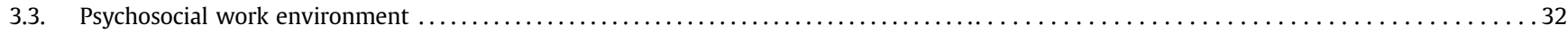

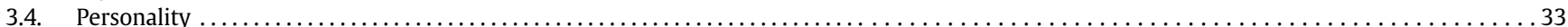

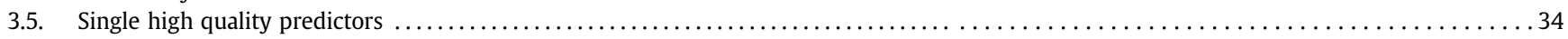

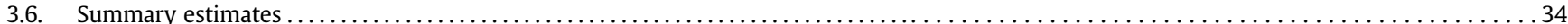

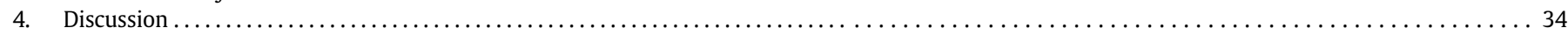

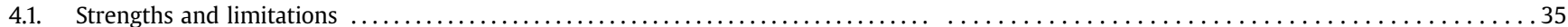

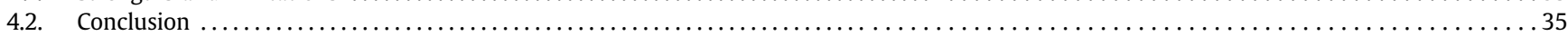

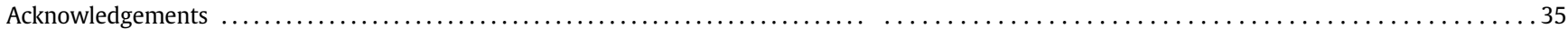

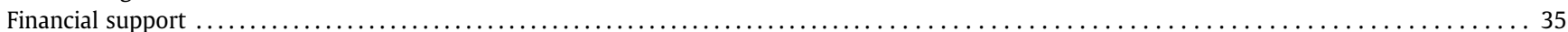

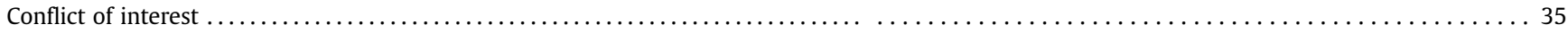

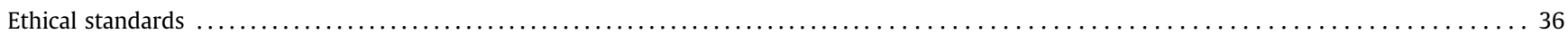

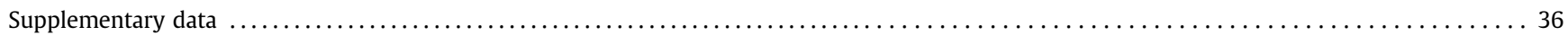

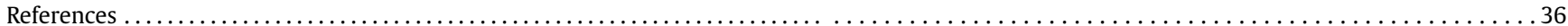

\section{Introduction}

Mental disorders are the single largest cause of work disability in many countries, and account for almost half of all new claims (OECD, 2010). Of mental disorders, depression has one of the highest lifetime and 12-month prevalence, and is associated with substantial functional impairment (Kessler et al., 1994, 2003, 2015; Wang et al., 2010). However, depression alone is rarely the cause of permanent work disability (Ahola et al., 2011), and therefore research on the factors are associated with return to work (RTW) after an episode of depression-related work disability is important in order to minimize adverse outcomes.

To date, research on these prognostic factors has been diverse. One review found strong evidence of slower RTW after work disability due to mental health problems at older ages. In addition, there was limited evidence of associations of male sex, previous sickness absence, low recovery expectations, and low socioeconomic status with continuing work disability (Cornelius et al., 2011). An earlier systematic review on disability onset showed strong evidence that the long duration of a depressive episode was associated with an increased risk of work disability (Lagerveld et al., 2010). Moderate evidence suggest also associations of older age, male sex, more severe depressive disorder, somatic and mental comorbidity, with work disability (Blank et al., 2008; Lagerveld et al., 2010). Longer duration and recurrence of sickness absence are also predictors of slower RTW (Dewa et al., 2014).

A limitation of previous research is its focus on mental health without specifically considering depression (Blank et al., 2008; Cornelius et al., 2011; Dewa et al., 2014) or on work disability onset rather than RTW (Lagerveld et al., 2010). Depression should be examined separately from other mental disorders, because compared with other nervous and mental disorders, depressionrelated disability generally affects more employees, lasts longer, and has a higher rate of recurrence and specific etiology (Dewa et al., 2002). In addition, most recent research is not covered by currently published meta-analyses.

In the present study, we aim to expand the current knowledge by examining the predictors of RTW after depression-related absence from work. Accordingly, we performed a systematic review of published research, reanalyzed published data, analyzed unpublished data from a large prospective study, and pooled the study-specific effect estimates using meta-analysis. Based on previous evidence, we hypothesized that both demographic (e.g., older age, male sex, low socioeconomic status) and illness-related factors (comorbidity, previous sickness absence, severity of depression) are related to RTW after depression-related sickness absence. In addition, we retrieved published studies on other potential predictive factors of RTW, such as personality and psychosocial factors, for our review and meta-analysis.

\section{Methods}

\subsection{Search strategy and selection criteria}

Two researchers (JE and MJ) carried out a systematic literature search including the terms "depression" and "return to work" to obtain relevant studies published by February 1, 2016 in PubMed, and by February 4, 2016 in Embase. The PubMed search identified 639 eligible studies. The corresponding number in the Embase search was 1106. Fig. 1 illustrates that 22 studies from PubMed and 5 additional studies from Embase met the inclusion criteria after full-text review. We also performed a review of the reference lists of the selected studies and earlier reviews (Blank et al., 2008; Lagerveld et al., 2010; Cornelius et al., 2011; Dewa et al., 2014), and a review of studies citing those (Thomson Reuters Web of Science database). This resulted in one additional study.

We included studies with RTW as the outcome variable. RTW was determined as the end of disability benefit compensation (usually register-based data), or as self-reported RTW. It was treated as a continuous variable (length of sickness absence or other work disability episodes), or as a binary variable (returned versus not returned). The participants in the included studies were receiving sickness or other work disability benefit due to a depressive disorder. Studies among participants with "common mental disorders" or "mental disorders" not specified as depression were excluded. Studies in which depression itself was a predictor of RTW were also excluded. Details of inclusion and exclusion criteria are provided in Table 1.

We found 14 studies that met the inclusion criteria. One study with depression and anxiety patients combined was re-included after contacting the authors, who then provided separate analyses of those with depression (anxiety excluded, Lammerts et al., 2016). This resulted in a total of 15 studies being included in the review (Fig. 1). Ebrahim et al., 2013 examined both predictors of short-term (up to 17 weeks and/or 26 weeks) and long-term (longer period, up to the age of 65) disability claims. From this study, we only included short-term disability claims, because these were more similar to the RTW outcomes of the other studies. Details of the included studies are presented in Supplementary Table 1.

\subsection{Quality assessment}

Quality was evaluated using Cochrane's "Tool to Assess Risk of Bias in Cohort Studies" (Cochrane Methods) (Supplementary Table 2). We evaluated bias in the following domains: 


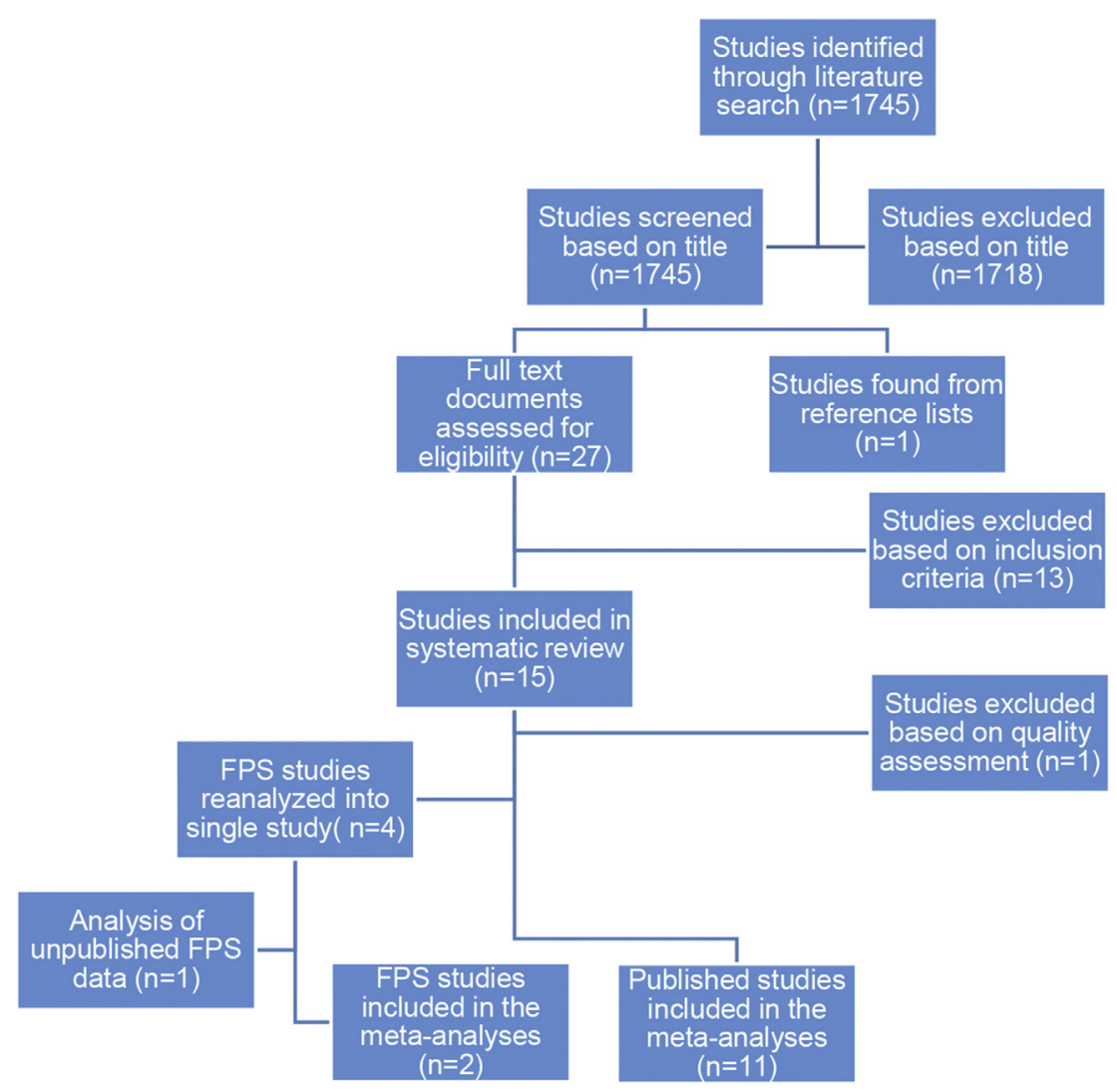

Fig. 1. Flowchart from search results to inclusion to review and meta-analysis. FPS=Finnish Public Sector.

Table 1

Inclusion and exclusion criteria.

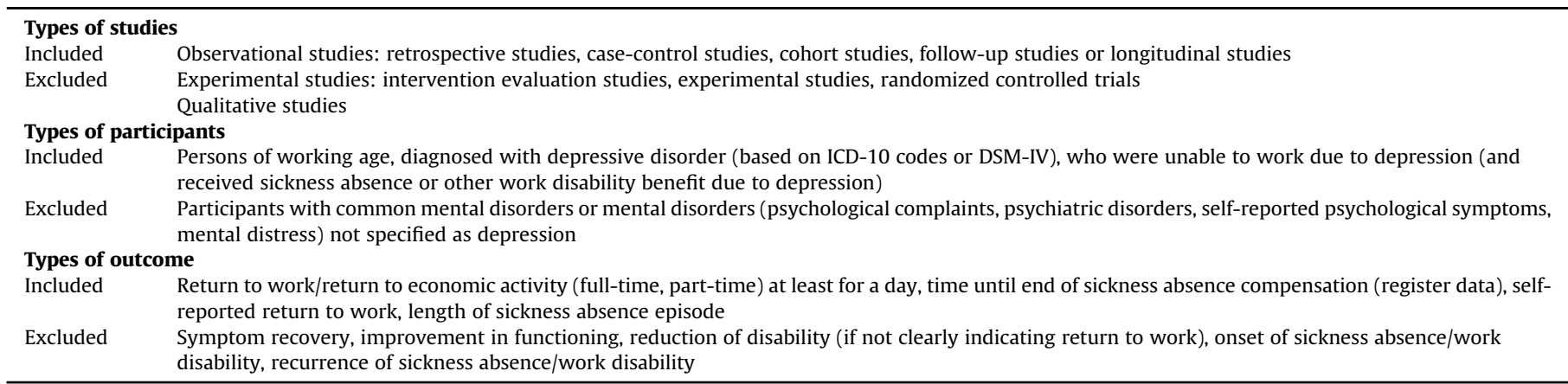

1. Can we be confident in the assessment of exposure (i.e., the predictor variables)?

2. Were the exposed and non-exposed cohorts selected from the same population?

3. Can we be confident that the outcome of interest was not present at the start of the study?

4. Did the statistical analysis adjust for the confounding variables?

5. Can we be confident in the assessment of the presence or absence of confounding factors?

6. Can we be confident in the assessment of the outcome?

7. Was the follow-up of the cohorts adequate?

The studies were evaluated in relation to each question using a four-level scale: “definitely yes"," probably/mostly yes”, "probably/ mostly no", and "definitely no". The quality of the study/estimate was considered high if all domains were evaluated favorably.
One study (Koopmans et al., 2008) made no adjustment for confounding variables, and was thus evaluated as "not high quality" and excluded from the meta-analyses (Fig. 1). Since each study included several predictor/exposure variables, we also evaluated the quality of each of the estimates separately. Confounding was evaluated with regard to each of the estimates separately (Supplementary Table 2).

Additionally, we evaluated the confidence in an effect using the GRADE (the Grading of Recommendations Assessment, Development and Evaluation) approach (Higgins and Green, 2011).

\subsection{The Finnish Public Sector study}

Five of the studies included in the review were based on the Finnish Public Sector (FPS) cohort (Kronström et al., 2011; Virtanen et al., 2011; Ervasti et al., 2013, 2014, 2015). The register-based 
predictors of four studies were reanalyzed to obtain a single study for the meta-analysis (Virtanen et al., 2011; Ervasti et al., 2013, 2014, 2015). The survey-based predictors used in Kronström et al., 2011, were not reanalyzed, but used as such. Moreover, we additionally analyzed the association between psychosocial work environment and RTW after depression in the unpublished FPS data. The final number of studies included in the meta-analyses was 13 (11 published and 2 with FPS data) (Fig. 1).

The FPS cohort consists of the employees of 10 municipalities and 21 hospitals in Finland, and has been approved by the Ethics Committee of the Hospital District of Helsinki. In the re-analysis of the register-based predictors, we included the cohort members who were alive and of working age (18-65 years), were not on disability pension or old-age pension on January 1, 2005 (the beginning of the follow-up), and had at least one depressionrelated absence from work during the follow-up period from 2005 to the end of 2011 ( $n=10875$ ). Following the procedure described in detail in Ervasti et al. (2015), we excluded employees who had received benefits related to unemployment, studying, parenting, or job alternation (sabbatical) during the year of their disability benefit ( $\mathrm{n}=961$ ). After excluding those with missing information on predictor variables $(n=6)$, we were left with 9908 employees with 14101 episodes of absence due to depressive disorders.

The register-based predictors analyzed were: sex, age, occupational position (upper-grade non-manual; lower-grade nonmanual; manual work), education (high; intermediate; basic education), residence size $\left(<70 \mathrm{~m}^{2} ; 70-100 \mathrm{~m}^{2} ;>100 \mathrm{~m}^{2}\right)$, residence ownership (owner; renter), type of employment contract (permanent; temporary), psychiatric comorbidity, and somatic disease (at least one of the following: cardiovascular disease, musculoskeletal disorder, diabetes, asthma, cancer). These were derived from various register keepers, as described previously (Ervasti et al., 2013, 2014, 2015).

As regards psychosocial work environment, we used survey responses aggregated at the work-unit level and those assigned to each participant at the same work-unit. Following the procedure described in detail in Laine et al., 2009 and Mäntyniemi et al., 2012, each participant in the same work unit was given the same work unit-based score, regardless of their survey response status. Job strain (Karasek and Theorell, 1990) was operationalized as high (higher than median) job demands (work load; three items, scale 1-5), and low (lower than median) job control (decision latitude; nine items, scale 1-5). These factors were measured using a questionnaire survey in $2004,2006,2008$, or 2010 . We used the work-unit level aggregated survey responses closest to the absence episode. Job control and demands were used as continuous variables, but job strain was based on median split.

The study population consisted of those eligible for the questionnaire survey in 2004, who were alive and not on disability pension or old-age pension at the beginning of the follow-up (January 1, 2005), and who had at least one depression-related absence during the follow-up period from 2005 to the end of $2011(n=5624)$. We excluded employees from work units with less than three respondents, which resulted in an analytic sample of 5572 employees, with 8208 depression-related absence episodes (ICD-10 codes F32-F34). Participants had, on average, 1.5 depression-related absence episodes each $(S D=0.96$, range $1-11)$.

\subsection{Statistical analysis}

We used a two-stage meta-analysis (Riley et al., 2010) with study-specific estimates obtained from published studies and unpublished/reanalyzed FPS data during the first stage. The second stage was the analysis that pooled all the study-specific estimates.

\subsubsection{First-stage analysis}

For meta-analysis, we converted odds ratios (OR) and their 95\% CIs into relative risks (RR), using the formula (Grant, 2014):

$\mathrm{RR}=\mathrm{OR} /\left(1-\mathrm{p}_{0}+\left(\mathrm{p}_{0} \times \mathrm{OR}\right)\right)$, where $\mathrm{p}_{0}$ is the baseline risk.

When OR is adjusted for covariates, average baseline risk can be used (Grant, 2014). We used the total proportion of patients returning to work in each study as the "baseline risk". Hazard ratio (HR) is an estimate of the relative risk. Thus, further conversion of HRs was not necessary.

In the FPS data, when an episode of depression-related absence from work was noted, the length of the episode was determined as being from the start date of the episode until RTW (end of compensation for at least a day), disability pension with a diagnosis other than an F32-F34 code, old age pension, death, or the end of follow-up (31 December 2011); whichever came first.

To control for intra-individual correlation, we used Cox proportional hazard models for recurrent events to examine the associations between explanatory factors and RTW after mental disorder-related absence. This method of analysis allows each individual to contribute to more than one episode. Correlation between observations was taken into account by calculating standard errors using the robust sandwich variance estimate, which yields consistent estimates without making distributional assumption. The results are presented as HR and their 95\% confidence intervals (CI). Supplementary Table 1 shows the unadjusted HRs, and HRs adjusted for sex, age, education/occupational position, and somatic comorbidity. Due to multicollinearity, education and occupational position were not modeled simultaneously. The FPS data was analyzed using SAS 9.4 software.

\subsubsection{Second-stage analysis}

We used fixed effect meta-analysis to combine the results from the FPS data, and (converted) estimates of the previously published estimates evaluated as "high quality", as detailed in Supplementary Table 2. Fixed effects meta-analysis was chosen due to the small number of studies. When there is little information, random effects analysis provides poor estimates and exacerbates the possible biases of smaller studies. Fixed effects model is less affected, although strictly it is also inappropriate (Higgins and Green, 2011). Thus, as a sensitivity analysis, we also show the results of random effects meta-analyses.

We used relative risks (RR) as an indicator of effect size, and their 95\% CIs as an indicator of precision. We included the most adjusted estimate of each study into the meta-analyses. We examined the heterogeneity of the estimates by computing an $\mathrm{I}^{2}$ statistic, and presented the summary estimates of the fixed effect analyses. Stata 13 was used for meta-analysis.

\section{Results}

The total number of observations in the 11 published studies was 22199 (most adjusted models) to 22358 (least adjusted models). Prospective FPS data provided 8208 (unpublished) and 14101 (reanalyzed) additional observations from Finland. The study publication years ranged from 2003 to 2016. Of the published studies, seven were prospective, three were retrospective, and one was a nested cohort study. The follow-up time (in prospective studies) ranged from 10 months to 7 years, and $32-89 \%$ returned to work during the follow-up period. Of the published studies, five were from the Netherlands, two from Canada, and one from each of Denmark, Sweden, Japan and Finland.

Because the predictors varied between the studies, the metaanalyses included a varying number of observations, ranging from 
260 to 26348 , obtained from two to five studies. The least and most adjusted estimates are presented in Supplementary Table 1.

We found a total of 49 factors of which the predictive power over RTW after depression had been tested (Supplementary Table 1). These factors covered several domains of risk, including sociodemographic (age, sex, cohabitation, education, occupational position, income, residence size and ownership, supervisory position, full-time job), workplace (company size, type of industry/ sector), health behaviors (alcohol use, smoking, physical activity), clinical and illness-related (comorbidity, depression severity, recurrent vs. single episode depression, treatment received, physical functioning, bodily pain, general health, health-related quality of life, vitality, work limitations, recovery expectations, objective recovery, sickness absence duration), psychosocial (job control, job demands, job strain, social support at work, supervisor behaviors/ relationship with supervisor, relationship with colleagues, work motivation, job satisfaction), personality (neuroticism, openness, altruism/agreeableness, conscientiousness, locus of control, optimism, pessimism, interpersonal sensitivity, expression of emotions), and labor market (job insecurity, type of employment contract, part-time sick leave policy).

\subsection{Sociodemographic factors}

A total of seven studies provided estimates on sex, of which four estimates were of high quality $(\mathrm{n}=25793)$. The pooled RR from the high quality estimates was 1.02 (95\% CI 0.98-1.05) for women, suggesting no sex-related difference in RTW after depression. However, the $\mathrm{I}^{2}$ value indicating the heterogeneity of the pooled estimate was $90 \%$ ( $p<0.001)$. Thus, there was considerable variation between the studies (Table 2).

A total of five studies provided high quality estimates on age. Studies in which age was classified could not be included in the meta-analysis. The pooled RR of 0.85 (95\% CI 0.84-0.87) for a tenyear increase in age suggested that older age was associated with slower RTW after depression. Although all studies indicated an inverse relationship, there was considerable variation between them $\left(\mathrm{I}^{2}\right.$ value was $94 \%, \mathrm{p}<0.001$. (Table 2 ).

Three studies provided estimates on white-collar vs. blue-collar occupational positions. Two of these estimates were of high quality ( $\mathrm{n}=24609$ ), and their pooled RR was 1.00 (95\% CI 0.96-1.04) for white-collar occupations, suggesting no association between occupational position and RTW. There was considerable variation $\left(\mathrm{I}^{2}=97 \%, \mathrm{p}<0.001\right)$ between the studies with FPS demonstrating a positive association, while Ebrahim et al., 2013 demonstrated an inverse association between high occupational position and RTW (Table 2.) With regard to other socioeconomic status indicators, Ebrahim et al., 2013 found that higher income was associated with slower RTW, and FPS found that higher education was associated with quicker RTW. Consistent with FPS, Vemer et al., 2013 found that supervisory position was associated with quicker RTW, and Lammerts et al., 2016 that higher income was associated with quicker RTW.

Two studies (Vemer et al., 2013; Lammerts et al., 2016) were available to examine the effect of cohabitation on RTW after depression, but in only one of these was the estimate considered to be of high quality, thus we did not conduct a meta-analysis. Neither study suggested an association between cohabitation and RTW.

\subsection{Clinical and illness-related factors}

Three out of four studies provided high quality estimates of the effect of comorbid anxiety $(n=564)$. The pooled RR of the three studies was 0.84 (95\% CI $0.61-1.15)$ suggesting no association between comorbid anxiety and RTW after depression. Here also, we observed substantial variation between studies $\left(\mathrm{I}^{2}=74 \%, \mathrm{p}=0.02\right)$ (Table 2).

Three studies provided high quality estimates on any psychiatric comorbidity ( $\mathrm{n}=25694)$. The pooled $\mathrm{RR}$ was $0.86(95 \% \mathrm{CI}$ $0.83-0.88$ ), indicating that any psychiatric comorbidity was inversely related to RTW after depression. However, once again there was considerable variation between the studies $\left(\mathrm{I}^{2}=96 \%\right.$, $\mathrm{p}<0.001$ ), and random effect model produced non-significant pooled estimate (Table 2.)

Two studies $(\mathrm{n}=24609)$ provided estimates on somatic comorbidity. The pooled RR was 0.80 (95\% CI $0.77-0.83$ ), suggesting slower RTW after depression among people with somatic comorbidity. No significant heterogeneity was observed between the studies $\left(\mathrm{I}^{2}=0 \%, \mathrm{p}=0.83\right.$. (Table 2 ).

Three out of four studies provided high quality estimates of depression severity $(n=1301)$. Depression severity was measured on a continuous scale, with higher scores indicating more severe depression. The pooled RR was 0.96 (95\% CI 0.94-0.98), suggesting that more severe depression was associated with slower RTW. We observed considerable heterogeneity between the studies $\left(\mathrm{I}^{2}=91 \%, \mathrm{p}<0.001\right.$. (Table 2$)$.

Two studies provided estimates of recurrent depression compared to single episodes, one of which (Ebrahim et al., 2013) was evaluated as being of high quality. In both studies, recurrent depression was associated with slower RTW compared to single episodes.

Single high quality estimates suggested that comorbid substance dependence was associated with slower RTW (HR $=0.59$, 95\% CI 0.36-0.96, Nordenskjöld et al., 2013). In the same study, not responding to electroconvulsive therapy (ECT, $\mathrm{HR}=0.42,95 \% \mathrm{CI}$ 0.25-0.69), less complete improvement with ECT (HR $=0.42,95 \%$ CI $0.25-0.69)$, benzodiazepine treatment $(\mathrm{HR}=0.36,95 \% \mathrm{CI}$ $0.25-0.52$ ), and longer sickness absence before ECT (HR $=2.89,95 \%$ CI 1.68-4.97) were also associated with slower RTW. In addition, Ogawa et al., 2013 found that sickness absence duration was associated with slower RTW (OR $=0.91,95 \%$ CI $0.84-0.99$ ), but since the measures were different (Nordensjköld et al., 2013 used a classified and Ogawa et al., 2013 used a continuous measure), we could not conduct a meta-analysis.

As regards treatment, Ebrahim et al., 2013 found that undergoing psychotherapy was associated with slower RTW after shortterm sickness absence (HR $=0.81,95 \%$ CI 0.68-0.97), and Dewa et al., 2003 found that as antidepressant use became more complex (switched medication, more than one prescription, two prescriptions for different antidepressants) the odds of RTW became lower $(\mathrm{OR}=0.16,95 \% \mathrm{CI} 0.07-0.39)$.

\subsection{Psychosocial work environment}

Three studies provided estimates on job control/decision latitude, of which two were evaluated as being of high quality. Since Vemer et al., 2013 used a continuous variable, we analyzed FPS data accordingly. In FPS, higher job control was associated with quicker RTW (HR = 1.09, 95\% CI 1.00-1.18), but Vemer et al., 2013 found no association between decision latitude and $\mathrm{RTW}(\mathrm{HR}=0.99,95 \% \mathrm{CI}$ 0.97-1.01). The pooled RR was 1.00 (95\% CI 0.98-1.02) suggesting no association between job control and RTW after depression, with significant heterogeneity between the studies $\left(\mathrm{I}^{2}=80 \%, \mathrm{p}=0.03\right)$ (Table 2). In FPS, also higher job strain was associated with slower RTW (HR $=0.94,95 \%$ CI 0.89-0.99).

Two studies provided estimates of social support. The estimate was evaluated as being of high quality in Vemer et al., 2013, and high social support was associated with quicker RTW $(\mathrm{HR}=1.08$, 95\% CI 1.01-1.15). Hees et al., 2012 showed that work motivation $(\mathrm{OR}=1.87,95 \%$ CI 1.18-2.96) was associated with quicker RTW. 
Table 2

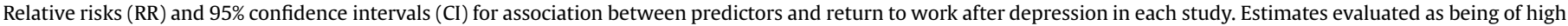
quality were included. FPS=Finnish Public Sector Study.

\begin{tabular}{|c|c|c|c|c|c|}
\hline Sociodemographics & $\mathrm{RR}$ & $95 \% \mathrm{CI}$ & Relative weight, \% & I-squared, \% (p-value) & Quality of evidence (GRADE) \\
\hline \multicolumn{6}{|l|}{ Women $($ ref $=$ men $)$} \\
\hline Dewa et al. & 1.07 & $0.98,1.14$ & 20.9 & & \\
\hline Ebrahim et al. & 0.92 & $0.87,0.97$ & 39.4 & & \\
\hline Vemer et al. & 0.49 & $0.30,0.81$ & 0.5 & & \\
\hline FPS & 1.10 & $1.04,1.16$ & 39.2 & & \\
\hline Overall fixed & 1.02 & $0.98,1.05$ & 100.0 & $90.3(<0.001)$ & + Very low ${ }^{\mathrm{a}}$ \\
\hline Overall random & 0.98 & $0.86,1.12$ & & & \\
\hline \multicolumn{6}{|l|}{ Age (per 10 year increase) } \\
\hline Dewa et al. & 0.95 & $0.93,1.00$ & 26.5 & & \\
\hline Ebrahim et al. & 0.90 & $0.88,0.97$ & 15.0 & & \\
\hline Vemer et al. & 0.82 & $0.66,1.00$ & 0.9 & & \\
\hline FPS & 0.80 & $0.87,0.82$ & 56.7 & & \\
\hline Lammerts et al. & 0.82 & $0.67,0.97$ & 1.0 & & \\
\hline Overall fixed & 0.85 & $0.84,0.87$ & 100.0 & $93.9(<0.001)$ & + Very low ${ }^{\mathrm{a}}$ \\
\hline Overall random & 0.86 & $0.78,0.95$ & & & \\
\hline \multicolumn{6}{|c|}{ High occupational position (ref = low) } \\
\hline Ebrahim et al. & 0.85 & $0.79,0.91$ & 34.0 & & \\
\hline FPS & 1.08 & $1.03,1.14$ & 66.0 & & \\
\hline Overall fixed & 1.00 & $0.96,1.04$ & 100.0 & $96.6(<0.001)$ & + Very low ${ }^{\mathrm{a}}$ \\
\hline Overall random & 0.96 & $0.76,1.21$ & & & \\
\hline \multicolumn{6}{|c|}{ Clinical and illness-related factors } \\
\hline \multicolumn{6}{|c|}{ Comorbid anxiety $($ ref $=$ no) } \\
\hline Hees et al. & 0.25 & $0.08,0.79$ & 8.2 & & \\
\hline Nordenskjöld et al. & 0.99 & $0.70,1.39$ & 92.2 & & \\
\hline Overall fixed & 0.88 & $0.64,1.23$ & 100.0 & $80.4(0.024)$ & + Very low ${ }^{a}$ \\
\hline Overall random & 0.56 & $0.15,2.11$ & & & \\
\hline \multicolumn{6}{|c|}{ Any psychiatric comorbidity $($ ref $=$ no $)$} \\
\hline Dewa et al. & 1.02 & $0.94,1.07$ & 26.2 & & \\
\hline Ebrahim et al. & 0.90 & $0.84,0.97$ & 20.9 & & \\
\hline FPS & 0.77 & $0.74,0.81$ & 52.9 & & \\
\hline Overall fixed & 0.86 & $0.83,0.88$ & 100.0 & $96.0(<0.001)$ & + Very low ${ }^{\mathrm{a}}$ \\
\hline Overall random & 0.89 & $0.75,1.06$ & & & \\
\hline \multicolumn{6}{|c|}{ Somatic comorbidity $($ ref $=$ no $)$} \\
\hline Ebrahim et al. & 0.81 & $0.73,0.90$ & 14.7 & & \\
\hline FPS & 0.80 & $0.77,0.84$ & 85.3 & & \\
\hline Overall fixed & 0.80 & $0.77,0.83$ & 100.0 & $0.0(0.83)$ & ++ Moderate $^{\mathrm{b}}$ \\
\hline Overall random & 0.80 & $0.77,0.83$ & & & \\
\hline \multicolumn{6}{|c|}{ Depression severity (cont.) } \\
\hline Dewa et al. & 0.83 & $0.78,0.89$ & 8.3 & & \\
\hline Hees et al. & 0.95 & $0.92,0.98$ & 36.0 & & \\
\hline Vemer et al. & 0.98 & $0.96,1.01$ & 55.7 & & \\
\hline Overall fixed & 0.96 & $0.94,0.98$ & 100.0 & $90.6(<0.001)$ & + Very low $w^{a}$ \\
\hline Overall random & 0.93 & $0.86,0.99$ & & & \\
\hline \multicolumn{6}{|c|}{$\begin{array}{l}\text { Work-related psychosocial factors } \\
\text { Job control (cont.) }\end{array}$} \\
\hline Vemer et al. & 0.99 & $0.97,1.01$ & 94.4 & & \\
\hline FPS & 1.09 & $1.00,1.18$ & 5.6 & & \\
\hline Overall fixed & 1.00 & $0.98,1.02$ & 100.0 & $79.6(0.03)$ & + Very low ${ }^{a}$ \\
\hline Overall random & 1.03 & $0.94,1.13$ & & & \\
\hline \multicolumn{6}{|c|}{ Personality factors } \\
\hline \multicolumn{6}{|c|}{ Conscientiousness (cont.) } \\
\hline Lammerts et al. & 1.09 & $0.91,1.26$ & 5.4 & & \\
\hline Hees et al. & 1.05 & $1.01,1.09$ & 94.5 & & \\
\hline Overall fixed & 1.06 & $1.02,1.10$ & 100.0 & $0.0(0.69)$ & ++ Moderate $^{\mathrm{b}}$ \\
\hline Overall random & 1.06 & $1.02,1.10$ & & & \\
\hline
\end{tabular}

a Downgraded due to unexplained heterogeneity between the studies.

b Upgraded due to low risk of bias, and no heterogeneity between the estimates.

A study by Nieuwenhuijsen et al., 2004 showed that among depressed employees (Depression subscale >12; Depression Anxiety Stress Scale [Lovibond and Lovibond, 1993; Nieuwenhuijsen et al., 2003; as cited in Nieuwenhuijsen et al., 2004]), supervisor communication with the employee $(\mathrm{HR}=1.6,95 \% \mathrm{CI} 0.8-3.2)$ was not associated with quicker RTW.

\subsection{Personality}

Personality was self-assessed in two studies $(\mathrm{n}=278)$, using the NEO-Five Factor Inventory (Costa and McCrae, 1995; Hoekstra et al.,
1996 as cited in Hees et al., 2012; Lammerts et al., 2016). Five characteristic were examined in these studies: neuroticism, extraversion, openness, altruism/agreeableness, and conscientiousness. For conscientiousness, the studies provided high quality estimates, but for the rest of the characteristics, only unadjusted estimates were available (extraversion only in Lammerts et al., 2016). High conscientiousness (pooled $\mathrm{RR}=1.06,95 \% \mathrm{CI} 1.02-1.10$ ) was associated with quicker RTW. There was no heterogeneity between the studies $\left(\mathrm{I}^{2}=0 \%, \mathrm{p}>0.69\right)$, but the relative weight of the study by Hees et al., 2012 was 95\%, whereas the weight of Lammerts et al., 2016 study was only 5\% (Table 2.). 
In single studies with high quality estimates, higher extraversion $(\mathrm{OR}=1.52,95 \% \mathrm{CI}$ 1.03-2.24, Lammerts et al., 2016), and lower pessimism (HR $=0.69,95 \%$ CI 0.50-0.96, Kronström et al., 2011) were also associated with slower RTW. The positive effect of optimism on quicker RTW was robust to adjustment for other covariates ( $\mathrm{HR}=1.30,95 \% \mathrm{CI} 1.01-1.66)$, but the effect was diluted after adjusting for pessimism ( $\mathrm{HR}=1.12,95 \% \mathrm{CI} 0.85-1.48$ ) (Kronström et al., 2011). The study by Ogawa et al., 2013 demonstrated an association between low interpersonal sensitivity and quicker RTW $(\mathrm{OR}=6.52,95 \%$ CI 1.52-28.5).

\subsection{Single high quality predictors}

Kronström et al., 2011 examined the association between health behaviors (alcohol use, smoking, and physical activity) and RTW after depression, and found neither of these factors to predict RTW.

Vemer et al., 2013 and Lammerts et al., 2016 reported no association between perceived job insecurity and time to RTW. In the FPS data, temporary employment contracts were, however, associated with slower RTW (HR $=0.84,95 \%$ CI 0.80-0.87). In the study by Lammerts et al., 2016, having no job contract was also associated with lower odds of RTW (OR $=0.33,95 \%$ CI $0.15-0.70$ ).

Two studies reported estimates on part-time sick leave, but with different measures (part-time sick leave: yes/no; proportion of sickness absence of the total working hours: continuous). Part-time sick leave was not associated with quicker RTW among depressed employees in either of the two studies ( $\mathrm{HR}=1.42,95 \% \mathrm{CI}$ 01.42-4.29, Høgelund et al., 2012; OR =0.99, 95\% CI 0.97-1.00, Hees et al., 2012). However, Vemer et al., 2013 found that having a full-time job was associated with slower RTW ( HR $=0.53,95 \% \mathrm{CI}$ 0.34-0.83).

\subsection{Summary estimates}

The summary estimates are shown in Fig. 2. Higher age, psychiatric and somatic comorbidity, more severe depression, and low conscientiousness were predictive of slower RTW after depressionrelated absence. As a sensitivity analysis, we performed the metaanalyses excluding the FPS data. The results were largely similar to those reported earlier (Supplementary Table 3).

\section{Discussion}

This systematic review and meta-analysis found low to moderate quality evidence that clinical and illness-related factors such as somatic and psychiatric comorbidity, as well as depression severity were associated with slower RTW.

Older age as a predictor of RTW corresponds to earlier systematic reviews about RTW after mental (Cornelius et al., 2011; Nigatu et al., 2017), but also somatic (Cancelliere et al., 2016; Gragnano et al., 2017) health problems. In a study conducted with the FPS data, older employees were remarkably less likely to RTW after depression than younger employees, whereas the agedifference was smaller in other common mental disorders (Mattila-Holappa et al., 2017). However, considerable heterogeneity between studies decreased the strength of evidence. The strength of the evidence regarding other sociodemographic factors was even weaker: we found that sex was not associated with return to work after depression, but the results were inconsistent, and there was considerable heterogeneity between the studies. Female sex has previously been associated with slower RTW in general (Cancelliere et al., 2016), but Gragnano et al., 2017 concluded that being female was a risk factor for somatic but not for mental disorders. As regards the role of socioeconomic status, two large studies provided conflicting results. In the Finnish study (FPS), high occupational position was associated with quicker RTW, whereas in a Canadian study (Ebrahim et al., 2013), the association was reversed. The difference between social security policies in Finland and Canada may have contributed to these controversial results. In a recent systematic review, high socioeconomic status was associated with faster RTW across various diseases (Gragnano et al., 2017).

Of the clinical factors, we found low to moderate evidence that somatic comorbidity was associated with slower RTW. People with somatic comorbidity were at an approximately 25\% higher risk of slower return than depressed people without somatic comorbidity. Psychiatric comorbidity and severity of depression were also associated with slower RTW, but the considerable heterogeneity between studies suggests that the findings may not be robust. The findings related to comorbidity and disease severity correspond to evidence found in earlier systematic reviews regarding the onset of work disability among people with all types of common mental disorders (Blank et al., 2008; Lagerveld et al., 2010) and also RTW after cardiovascular diseases, cancers (Gragnano et al., 2017; van Muijen et al., 2013) and traumatic hand injuries (Shi et al., 2014). Because recovery from more severe and complex depression takes a longer time, the link between illness-related factors and RTW seems plausible.

\author{
Women vs men, 4 studies \\ Age per 10 years, 5 studies \\ High occupational position vs. Iow, 2 studies \\ Anxiety vs. no, 2 studies \\ Any psychiatric comorbidity vs. no, 3 studies \\ Somatic comorbidity vs. no, 2 studies \\ Depression severity (per 1 unit increase), 3 studies \\ Job control (per 1 unit increase), 2 studies \\ Conscientiousness (per 1 unit increase), 2 studies
}

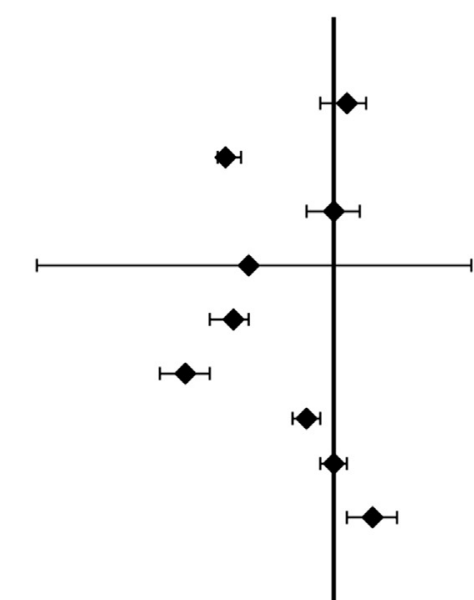

$\operatorname{RR}(95 \% \mathrm{CI})$

$1.02(0.98,1.05)$

$0.85(0.84,0.87)$

$1.00(0.96,1.04)$

$0.84(0.61,1.15)$

$0.86(0.83,0.88)$

$0.80(0.77,0.83)$

$0.96(0.94,0.98)$

$1.00(0.98,1.02)$

$1.06(1.02,1.10)$

Lower probability of return to work

Higher probability of return to work

Fig. 2. Pooled estimates (relative risk, RR) and 95\% CIs for the association between socio-demographic, clinical and psychosocial factors and RTW after depression. 
Of personality characteristics, moderate quality evidence from two studies without significant heterogeneity suggested that higher conscientiousness was associated with quicker RTW. Due to lack of high-quality studies, we were unable to perform metaanalysis on other personality traits such as neuroticism often linked with depression (Klein et al., 2011). This does not imply that they do not matter, but that more high-quality studies are needed to demonstrate their role in RTW after depression. Personality may affect depression recovery per se, but individuals' intentions and perceptions regarding their working capacity and RTW also play a part. Thus, the link between personality and RTW is plausible.

Evidence regarding work- and labor market-related factors was largely lacking. Single studies suggested that adverse psychosocial factors at work, such as high job strain, lack of social support and vulnerable labor market position, as indicated by temporary or no employment, were associated with slower return from depressionrelated absence from work, but more research is needed to demonstrate the role of these factors in RTW after depression. More evidence exists on the role of physical and psychosocial work environment and RTW after somatic than mental disease (van Muijen et al., 2013; Cancelliere et al., 2016; Gragnano et al., 2017).

We also observed a lack of evidence concerning treatment and RTW. Ebrahim et al., 2013 found that psychotherapy was associated with slower RTW after short-term absence, but quicker RTW after long-term absence. Dewa et al., 2003 found that more complex antidepressant use was associated with slower RTW. In both of these studies, and in general when examining the effects of treatment, depression severity causes confounding by indication, where more complex treatment is a marker for more complex depression, leading to misinterpretations about the effects of treatment on RTW.

\subsection{Strengths and limitations}

This is the first systematic review to provide quantitative estimates of factors contributing to RTW after depression. The data were both published and unpublished, which enabled us to include as many predictors as possible, and also somewhat reduced publication bias. Publication bias refers to a procedure in which authors publish only the factors that have been found to be statistically significant.

Only 15 studies were available for review, of which only two to five provided high-quality estimates for meta-analysis. Underreporting of the number of factors actually studied compared to those published is possible. Sometimes only statistically significant estimates are included in the final statistical models. Future studies should be more precise in reporting all estimates, in spite of their statistical significance.

The majority of identified predictors of RTW were unspecific and predict also RTW after other mental or somatic disease (Nigatu et al., 2017; Gragnano et al., 2017; Cancelliere et al., 2016). The general RTW process thus seems to be rather similar across various diseases, but also disease-specific differences were found. For example, the role of work relationships seemed more crucial after mental than somatic work disability (Gragnano et al., 2017). Of the 13 studies included, only two to five provided high quality estimates on the same prognostic factors. The studies included were conducted in six different countries, each of which had their own structure of social benefits as well as other country-specific differences. This may have had an impact on both the onset of depression-related work disability and on RTW, resulting in heterogeneous results. Studies from Finland, Canada and the Netherland were dominant, which limits the generalizability of the results.

While the study design was good (prospective) in most of the studies ( 8 out of 11), in four out of eight of these prospective studies, the follow-up time was 1.5 years or less. This relatively short follow-up time could have biased our findings.

Finally, in FPS and also in some other included studies, the definition of RTW was based on end of disability benefit. Although in FPS, we excluded those had received benefits related to unemployment, studying, parenting, or job alternation during the year of their disability benefit in order to ensure that these participant had actually returned to work rather than to some other activity, some ambiguity remains as to whether these participant actually returned to work. We could have chosen to call the outcome variable as 'return to economic activity', but for convenience and clarity, we chose RTW.

\subsection{Conclusion}

We found few high quality predictors of return to work after depression-related absence, and observed considerable heterogeneity between the studies. Previous systematic reviews with narrative analyses have suggested that absence from work and later RTW are, for a large part, related to non-medical conditions (Blank et al., 2008; Cornelius et al., 2011). Our meta-analysis contradicts these previous conclusions by suggesting that clinical and illnessrelated factors were the most consistent predictors of RTW after depression. Therefore, optimal treatment seems to be the most important tool for reducing the duration of sickness absence due to depression. This is in line with reviews on interventions to enhance RTW after mental health-related absence from work, which have found that cognitive behavioral therapy may enhance RTW (Odeen et al., 2012; Nieuwenhuijsen et al., 2014; Joyce et al., 2016).

There is insufficient evidence regarding the role of workplace and labor market factors, and RTW after depression. A previous review evaluating the effectiveness of RTW interventions among depressed employees found that adding a work-directed intervention (work modification, coaching) to a clinical intervention (medication, therapy) reduced the number of sickness absence days more than clinical intervention alone (Nieuwenhuijsen et al., 2014). Based on that, it may be beneficial to offer combined interventions, where also work-related factors are taken into account. However, there is a dearth of observational studies on the predictors of RTW after depression and the existing evidence suffers from low quality. Future research should pay attention to quality aspects and particularly focus on the role of workplace and labor market factors as well as individual and clinical characteristics on RTW after depression.

\section{Acknowledgements}

We thank MSc Lieke Lammerts and her associates for providing us with the reanalyses of their previously published article.

\section{Financial support}

J Ervasti and M Virtanen received funding from the Academy of Finland (grant numbers 292824, 258598). M Joensuu received funding from the Social Insurance Institution of Finland. M Kivimäki and J Vahtera are supported by the NordForsk (the Nordic Programme on Health and Welfare).

\section{Conflict of interest}

None. 


\section{Ethical standards}

The authors assert that all procedures contributing to this work comply with the ethical standards of the relevant national and institutional committees on human experimentation and with the Helsinki Declaration of 1975, as revised in 2008.

\section{Appendix A. Supplementary data}

Supplementary data related to this article can be found at http:// dx.doi.org/10.1016/j.jpsychires.2017.07.024.

\section{References}

Ahola, K., Virtanen, M., Honkonen, T., Isometsä, E., Aromaa, A., Lönnqvist, J., 2011 Common mental disorders and subsequent work disability: a population-based health 2000 study. J. Affect. Disord. 134, 365-372.

Blank, L., Peters, J., Pickvance, S., Wilford, J., MacDonald, E., 2008. A systematic review of the factors which predict return to work for people suffering episodes of poor mental health. J. Occup. Rehabil. 18, 27-34.

Cancelliere, C., Donovan, J., Stochkendahl, M.J., Biscardi, M., Ammedolia, C., Myburgh, C., Cassidy, J.D., 2016. Factors affecting return to work after injury or illness: best ecidence synthesis of systematic reviews. Chiropr. Man. Ther. 28, 32.

Cochrane Methods. Tool to assess risk of bias in cohort studies. (http://methods. cochrane.org/bias/sites/methods.cochrane.org.bias/files/uploads/Tool\%20to\% 20Assess\%20Risk\%20of\%20Bias\%20in\%20Cohort\%20Studies.pdf) Accessed 17 August 2016.

Cornelius, L.R., van der Klink, J.J., Groothoff, J.W., Brouwer, S., 2011. Prognostic factors of long-term disability due to mental disorders: a systematic review. J. Occup. Rehabil. 21, 259-274.

Dewa, C.S., Goering, P., Lin, E., Paterson, M., 2002. Depression-related short-term disability in an employed population. J. Occup. Environ. Med. 44, 628-633.

Dewa, C.S., Hoch, J.S., Lin, E., Paterson, M., Goering, P., 2003. Pattern of antidepressant use and duration of depression-related absence from work. Br. J. Psychiatry 183, 507-513.

Dewa, C.S., Loong, D., Bonato, S., 2014. Work outcomes of sickness absence related to mental disorders: a systematic literature review. BMJ Open 4, e005533.

Ebrahim, S., Guyatt, G.H., Walter, S.D., Heels-Ansdell, D., Bellman, M., Hanna, S.E., Patelis-Siotis, I., Busse, J.W., 2013. Association of psychotherapy with disability benefit claim closure among patients disabled due to depression. PLoS One 8, e67162.

Ervasti, J., Vahtera, J., Pentti, J., Oksanen, T., Ahola, K., Kivimäki, M., Virtanen, M. 2013. Depression-related work disability: socioeconomic inequalities in onset, duration and recurrence. PLoS One 8, e79855.

Ervasti, J., Vahtera, J., Virtanen, P., Pentti, J., Oksanen, T., Ahola, K., Kivimäki, M., Virtanen, M., 2014. Is temporary employment a risk factor for work disability due to depressive disorders and delayed return to work? The Finnish public sector study. Scand. J. Work Environ. Health 40, 343-352.

Ervasti, J., Vahtera, J., Pentti, J., Oksanen, T., Ahola, K., Kivekäs, T., Kivimäki, M. Virtanen, M., 2015. Return to work after depression-related absence by employees with and without other health conditions: a cohort study. Psychosom. Med. 77, 126-135.

Gragnano, A., Negrini, A., Miglioretti, M., Corbiére, M., 2017. Common prychosocial factors predicting return to work after common mental disorders, cardiovascular diseases, and cancers: a review of reviews supporting a cross-disease approach. J. Occup. Rehabil. http://dx.doi.org/10.1007/s10926-017-9714-1. Epub ahead of print.

Grant, R.L., 2014. Converting an odds ratio to a range of plausible relative risks for better communication of research findings. BMJ 348, f7450.

Hees, H.L., Koeter, M.W., Schene, A.H., 2012. Predictors of long-term return to work and symptom remission in sick-listed patients with major depression. J. Clin. Psychiatry 73, e1048-e1055.

Higgins, J.P.T., Green, S. (Eds.), 2011. Cochrane Handbook for Systematic Reviews of Interventions Version 5.1.0 [Updated March 2011]. The Cochrane Collaboration. (http://handbook.cochrane.org/). Accessed 8 September 2016.

Høgelund, J., Holm, A., Eplov, L.F., 2012. The effect of part-time sick leave for employees with mental disorders. J. Ment. Health Policy Econ. 15, 157-170.

Joyce, S., Modini, M., Christensen, H., Mykletun, A., Bryant, R., Mitchell, P.B., Harvey, S.B., 2016. Workplace interventions for common mental disorders: a systematic meta-review. Psychol. Med. 46, 683-697.

Karasek, R., Theorell, T., 1990. Healthy Work: Stress, Productivity, and the Reconstruction of Working Life. Basic Books, New York, NY.

Kessler, R.C., McGonagle, K.A., Zhao, S., Nelson, C.B., Hughes, M., Eshleman, S., Wittchen, H.U., Kendler, K.S., 1994. Lifetime and 12-month prevalence of DSMiii-R psychiatric disorders in the United States. Results from the national comorbidity survey. Arch. Gen. Psychiatry 51, 8-19.

Kessler, R.C., Berglund, B., Demler, O., Jin, R., Koretz, D., Merikangas, K., Rush, A.J. Walters, E.E., Wang, P.S.; National Comorbidity Survey Replication, 2003. The epidemiology of major depressive disorder. Results from the National
Comorbidity Survey Replication (NCR-R). JAMA 289, 3095-3105.

Kessler, R.C., Sampson, N.A., Berglund, P., Gruber, M.J., Al-Hamzawi, A., Andrade, L., Bunting, B., Demyttenaere, K., Florescu, S., de Girolamo, G., Gureje, O., He, Y. Hu, C., Huang, Y., Karam, E., Kovess-Masfety, V., Lee, S., Levinson, D., Medina Mora, M.E., Moskalewicz, J., Nakamura, Y., Navarro-Mateu, F., Browne, M.A., Piazza, M., Posada-Villa, J., Slade, T., Ten Have, M., Torres, Y., Vilagut, G., Xavier, M., Zarkov, Z., Shahly, V., Wilcox, M.A., 2015. Anxious and non-anxious major depressive disorder in the world health organization world mental health surveys. Epidemiol. Psychiatr. Sci. 3, 210-226.

Klein, D.N., Kotov, R., Bufferd, S.J., 2011. Personality and depression: explanatory models and review of the evidence. Annu. Rev. Clin. Psychol. 7, 269-295.

Koopmans, P., Roelen, C.A., Groothoff, J.W., 2008 May. Sickness absence due to depressive symptoms. Int. Arch. Occup. Environ. Health 81 (6), 711-719.

Kronström, K., Karlsson, H., Nabi, H., Oksanen, T., Salo, P., Sjösten, N., Virtanen, M., Pentti, J., Kivimäki, M., Vahtera, J., 2011. Optimism and pessimism as predictors of work disability with a diagnosis of depression: a prospective cohort study of onset and recovery. J. Affect. Disord. 130, 294-299.

Lagerveld, S.E., Bültmann, U., Franche, R.L., van Dijk, F.J.H., Vlasveld, M.C., van der Feltz-Cornelis, C.M., Bruinvels, D.J., Huijs, J.J., Blonk, R.W., van der Klink, J.J., Nieuwenhuijsen, K., 2010. Factors associated with work participation and work functioning in depressed workers: a systematic review. J. Occup. Rehabil. 20, 275-292.

Laine, S., Gimeno, D., Virtanen, M., Oksanen, T., Vahtera, J., Elovainio, M. Koskinen, A., Pentti, J., Kivimäki, M., 2009. Job strain as a predictor of disability pension: the Finnish public sector study. J. Epidemiol. Community Health 63, 24-30.

Lammerts, L., Schaafsma, F.G., Eikelenboom, M., Vermeulen, S.J., van Mechelen, W. Anema, J.R., Penninx, B.W., 2016. Longitudinal associations between biopsychosocial factors and sustainable return to work of sick-listed workers with a depressive or anxiety disorder. J. Occup. Rehabil. 26, 70-79.

Mattila-Holappa, P., Ervasti, J., Joensuu, M., Ahola, K., Pentti, J., Oksanen, T. Vahtera, J., Kivimäki, M., Virtanen, M., 2017. Do predictors of return to work and recurrence of workdisability due to mental disorders vary by age? A cohort study. Scand. J. Public Health 45, 178-184.

Mäntyniemi, A., Oksanen, T., Salo, P., Virtanen, M., Sjösten, N., Pentti, J., Kivimäki, M. Vahtera, J., 2012. Job strain and the risk of disability pension due to musculoskeletal disorders, depression or coronary heart disease: a prospective cohort study of 69842 employees. Occup. Environ. Med. 69, 574-581.

Nieuwenhuijsen, K., Verbeek, J.H.A.M., de Boer, A.G.E.M., Blonk, R.W., van Dijk, F.J.H., 2004. Supervisory behaviours as a predictor of return to work in employees absent from work due to mental health problems. Occup. Environ. Med. 61, 817-823.

Nieuwenhuijsen, K., Faber, B., Verbeek, J.H., Neumeyer-Gromen, A., Hees, H.L., Verhoeven, A.C., van der Feltz-Cornelis, C.M., Bültmann, U., 2014. Interventions to improve return to work in depressed people. Cochrane Database Syst. Rev. 12 http://dx.doi.org/10.1002/14651858.CD006237.pub3.

Nigatu, Y.T., Liu, Y., Uppal, M., McKinney, S., Gillis, K., Rao, S., Wang, J., 2017. Prognostic factors for return to work of employees with common mental disorders: a meta-analysis of cohort studies. Soc. Psychiatry Psychiatr. Epidemiol. http:// dx.doi.org/10.1007/s00127-017-1402-0. Epub ahead of print.

Nordenskjöld, A., von Knorring, L., Brus, O., Engström, I., 2013. Predictors of regained occupational functioning after electroconvulsive therapy (ECT) in patients with major depressive disorder - a population based cohort study. Nord. J. Psychiatry 67, 326-333.

Odeen, M., Magnussen, L.H., Maeland, S., Larun, L., Eriksen, H.R., Tveito, T.H., 2012 Systematic review of active workplace interventions to reduce sickness absence. Occup. Med. 63, 7-16.

OECD, 2010. Sickness, Disability and Work: Breaking the Barriers. A Synthesis of Findings across OECD countries. OECD Publishing, Paris. http://ec.europa.eu/ health//sites/health/files/mental_health/eu_compass/reports_studies/disability_ synthesis_2010_en.pdf.

Ogawa, T., Shigemura, J., Yoshino, A., Nomura, S., 2013. Interpersonal sensitivity associated with return to work status following sick leave: a cross-sectional study among Japanese workers with major depressive disorder. Asian J. Psychiatry 6, 146-150.

Riley, R.D., Lambert, P.C., Abo-Zaid, G., 2010. Meta-analysis of individual participant data: rationale, conduct, and reporting. BMJ 340, c221.

Shi, Q., Sinden, K., MacDermid, J.C., Walton, D., Grewal, R., 2014. A systematic review of prognostic factors for return to work following work-related traumatic hand injury. J. Hand Ther. 27, 55-62.

van Muijen, P., Weevers, N.L., Snels, I.A., Duijts, S.F., Bruinvels, D.J., Schellart, A.J., van der Beek, A.J., 2013. Predictors of return to work and employment in cancer survivors: a systematic review. Eur. J. Cancer Care 22, 144-160.

Vemer, P., Bouwmans, C.A., Zijlstra-Vlasveld, M.C., van der Feltz-Cornelis, C.M., Hakkaart-Van Roijen, L., 2013. Let's get back to work: survival analysis on the return-to-work after depression. Neuropsychiatr. Dis. Treat. 9, 1637-1645.

Virtanen, M., Kawachi, I., Oksanen, T., Salo, P., Tuisku, K., Pulkki-Råback, L., Pentti, J., Elovainio, M., Vahtera, J., Kivimäki, M., 2011. Socio-economic differences in long-term psychiatric work disability: prospective cohort study of onset, recovery and recurrence. Occup. Environ. Med. 68, 791-798.

Wang, J., Smailes, E., Sareen, J., Fick, G.H., Schmitz, N., Patten, S.B., 2010. The prevalence of mental health disorders in the working population over the period of global economic crisis. Can. J. Psychiatry 55, 598-605. 